\title{
Cutis laxa with severe pulmonary, gastrointestinal and urinary anomalies
}

INSERM

\section{Source}

INSERM. (1999). Orphanet: an online rare disease and orphan drug data base. Cutis laxa with severe pulmonary, gastrointestinal and urinary anomalies. ORPHA:221145

A rare, genetic, dermis elastic tissue disorder characterized by generalized cutis laxa associated with severe, usually early-onset, pulmonary emphysema, frequent and severe gastrointestinal and genitourinary involvement (i.e. bladder/intestine diverticula and/or tortuosity, gastrointestinal fragility, hydronephrosis), and mild cardiovascular involvement (typically limited to peripheral pulmonary artery stenosis only). 